\title{
Tropical Ice Water Amount and Its Relations to Other Atmospheric Hydrological Parameters as Inferred from Satellite Data
}

\author{
Guosheng LiU And Judith A. CurRY \\ Program in Atmospheric and Oceanic Sciences and Department of Aerospace Engineering Sciences, \\ University of Colorado, Boulder, Colorado
}

(Manuscript received 26 May 1998, in final form 7 October 1998)

\begin{abstract}
An over-ocean ice water path (IWP) algorithm, using satellite Special Sensor Microwave Water Vapor Sounder (SSM/T-2) data, is presented for clouds during the Tropical Oceans Global Atmosphere Coupled Ocean-Atmosphere Response Experiment. In developing the retrieval algorithm, clouds are first divided into 10 classes based on their top temperatures and microwave radiative properties. Radiative transfer model simulations are then performed for the different classes to establish a relation between IWP and the depression of $150-\mathrm{GHz}$ brightness temperature. Correction to the effect of supercooled liquid water is done by incorporating data of liquid water path (LWP) retrievals from Special Sensor Microwave/Imager (SSM/I) and relative humidity profiles from the European Centre for Medium-Range Weather Forecasts analyses. The algorithm retrievals are compared with the analyses in the International Satellite Cloud Climatology Project (ISCCP) dataset. By using collocated SSM/T-2, SSM/I, and ISCCP data, the relations among IWP and other atmospheric hydrological properties including cloud-top temperature, LWP, rainfall rate, and precipitable water are investigated. The results indicate that IWP tends to increase with the decrease of cloud-top temperature and this correlation is particularly evident for precipitating clouds. LWP retrieved for nonprecipitating clouds has a similar tendency but only for those with top temperatures warmer than $0^{\circ} \mathrm{C}$. There is no clear relation between IWP and LWP. The ratio of IWP to total condensed water (IWP + LWP) for nonprecipitating clouds seems to be negatively correlated with cloudtop temperature on an average of a large data volume, but this relationship differs substantially among individual cases. Rainfall rate has a strong correlation with IWP. High values of IWP and LWP are always associated with high precipitable water although high precipitable water does not automatically correspond to high IWP or high LWP.
\end{abstract}

\section{Introduction}

A better understanding of cloud ice water content is important to climate research for improving our knowledge of cloud and precipitation processes and for validating global climate models (GCMs). The initiation and growth of ice particles are key microphysical processes in determining rainfall intensity (e.g., Rutledge and Hobbs 1983). For climate modeling purposes, cloud and precipitation processes need to be understood and parameterized over a scale of model grid size (order of $100 \mathrm{~km}$ ). Satellite remote sensing, therefore, is undoubtedly a needed tool. In a recent World Meteorological Organization report on "Measurements of Cloud Properties for Forecasts of Weather and Climate," Del Genio wrote (Del Genio 1997), "The most glaring absence of information is any kind of estimate of the global distribution of ice water path. State-of-the-art GCMs

Corresponding author address: Dr. Guosheng Liu, Dept. of Meteorology, The Florida State University, Tallahassee, FL 32306. E-mail: liug@met.fsu.edu with prognostic cloud water parameterizations do not come close to agreeing on whether there is globally more ice or liquid water in the atmosphere."

This study describes an over-ocean algorithm to retrieve ice water path (IWP) from satellite microwave measurements. Using satellite data we investigate the relationships among IWP and other atmospheric hydrological parameters, such as cloud liquid water, rainfall rate, etc. These relationships can be used to assist modelers developing cloud parameterizations and validating model outputs. This paper focuses particularly on these relations using satellite data collected in the Tropics during Tropical Oceans Global Atmosphere Coupled Ocean-Atmosphere Response Experiment (TOGA COARE) (Webster and Lukas 1992).

Studies of cloud ice water content have previously been conducted primarily using aircraft in situ measurements (e.g., Knollenberg et al. 1993; Heymsfield 1993). Recently, Heymsfield and McFarquhar (1996) and McFarquhar and Heymsfield (1996) investigated the microphysical characteristics and radiative properties of tropical cirrus using aircraft-measured data during the Central Equatorial Pacific Experiment (CEPEX). Most 
retrievals of ice water from remotely sensed data are still in the development stage. Minnis et al. (1993a,b) developed a method to retrieve cirrus cloud properties from satellite-observed visible and infrared data. Ground-based remote sensing of ice water content using radar and infrared radiometer was proposed by Matrosov et al. (1992, 1994). IWP over oceans was estimated by Lin and Rossow (1996) and Sheu et al. (1997) using multichannel satellite data including visible and infrared data from the International Satellite Cloud Climatology Project (ISCCP) (Rossow and Schiffer 1991) and microwave data from the Special Sensor Microwave/Imager (SSM/I). Lin and Rossow studied the seasonal variation of IWP in nonprecipitating clouds over global oceans, and Sheu et al. (1997) investigated the vertical distributions of hydrometeors for all clouds during TOGA COARE. In both studies, IWP for nonprecipitating clouds was calculated from the difference between ISCCP total water path and SSM/I liquid water path. Liu and Curry $(1996,1997)$ proposed a method to retrieve IWP and snowfall rate over high-latitude oceanic regions during winter using scattering signals in Special Sensor Microwave Water Vapor Sounder (SSM/ T-2) data. Using airborne Millimeter-Wave Imaging Radiometer (MIR) data, Liu and Curry (1998) retrieved IWP in TOGA COARE regions for 12 aircraft flight missions. The retrieved IWPs were compared with in situ measurements. Deeter (1997) also studied IWP retrieval using MIR data and proposed to retrieve both IWP and particle size distribution in cirrus using a combination of scattering signals in two different frequencies. While IWP is not retrieved directly, many precipitation algorithms utilize ice-scattering signatures for rain retrievals (e.g., Adler et al. 1993; Grody 1991; Petty 1994). Theoretical studies of ice water remote sensing using microwave radiative transfer model simulations have been done by Vivekanandan et al. (1991) for SSM/ I 85.5-GHz channel, and Evans and Stephens (1995a,b) and Evans et al. (1998) for submillimeter frequencies. Optimal frequencies for ice water retrieval in future satellite missions were proposed by Evans et al. (1998). Methods using visible channels have the advantage to be able to detect smaller ice particles, which is particularly useful for determining IWP in thin cirrus clouds. The frequencies proposed by Evans et al. (1998) are 630 and $880 \mathrm{GHz}$, which are also expected to have higher sensitivities to cirrus clouds than the frequencies available on SSM/T-2 (92-183 GHz).

In this study, we follow a similar IWP retrieval approach to that described by Liu and Curry (1998) while modifying and adopting the algorithm for satellite SSM/ T-2 data. By collocating SSM/T-2 data with ISCCP and $\mathrm{SSM} / \mathrm{I}$ data, we are able to investigate the relationships between IWP and other atmospheric hydrological parameters including cloud-top temperature, liquid water path (LWP), rainfall rate, and precipitable water. Interpretation and discussion of these relations are also given.

\section{Data descriptions}

The focus of this study is the tropical clouds during TOGA COARE Intensive Observing Period (IOP) from 1 November 1992 to 28 February 1993. Satellite datasets used are SSM/T-2, SSM/I, and ISCCP DX. SSM/ T-2 (Falcone et al. 1992) is a cross-track scanning radiometer at frequencies of 92,150, $183 \pm 1,183 \pm 3$, and $183 \pm 7 \mathrm{GHz}$. It makes 28 measurements across a scan line at $3^{\circ}$ increments with a swath width of 1480 $\mathrm{km}$. Only the center 20 pixels are used in this study to avoid possible interference by the glare obstruction panel as well as large scan angles. Data from 92 and 150 $\mathrm{GHz}$ are used for IWP retrieval. The spatial resolution at nadir is $88 \mathrm{~km}$ for $92 \mathrm{GHz}$ and $54 \mathrm{~km}$ for $150 \mathrm{GHz}$. SSM/T-2 was available only from DMSP F11 satellite during TOGA COARE IOP, providing a local sampling frequency of once per day on average.

$\mathrm{SSM} / \mathrm{I}$ is a conical scan radiometer with frequencies at $19.35,22.235,37$, and $85.5 \mathrm{GHz}$. LWP and rainfall rate are retrieved from SSM/I data based on methods described in Liu and Curry (1992, 1993, 1996). LWP retrieval is performed only for nonprecipitating clouds. Its retrievals are also used in part for assisting IWP retrieval when a mixed phase cloud is diagnosed to exist. Both LWP and rainfall retrievals are used to study the relations among cloud-top temperature, IWP, LWP, and rainfall rates. Precipitable water is retrieved from SSM/I data following the method of Petty (1994).

The DX version (Rossow et al. 1996) of the ISCCP dataset provides cloud-top temperature and optical depth, among other parameters. The temporal and spatial intervals of the DX sampling are $3 \mathrm{~h}$ and $30 \mathrm{~km}$. Cloud-top temperature is derived primarily from infrared radiance while a correction is applied using visible data during daytime. Cloud optical depths are retrieved from visible data using either a liquid water droplet model or an ice crystal model. The optical depth based on the first microphysics (called TAU) is produced for all daytime cloudy pixels and that based on the second microphysics (called TAUI) is produced for the daytime cloudy pixels whose cloud-top temperatures are lower than $273 \mathrm{~K}$ or their top pressures are lower than 440 $\mathrm{mb}$. It is noted that for mixed-phase clouds TAU is not the actual optical depth by liquid water droplets, nor is TAUI the actual optical depth by ice particles. For mixed-phase clouds TAU overestimates liquid water optical depth by counting ice particles as liquid droplets while TAUI overestimates ice water optical depth by counting liquid water droplets as ice particles.

In order to investigate the relations between IWP and other atmospheric hydrological properties, SSM/T-2 data are collocated with SSM/I and ISCCP data. Because SSM/I and SSM/T-2 are on the same platform (F11), their sampling time differences are only about 2 min. We used the nearest SSM/I pixel to match an SSM/ $\mathrm{T}-2$ pixel. Although the time difference is small between SSM/I and SSM/T-2 data, their collocation still has some 
uncertainties since SSM/I is a conically scanning radiometer and SSM/T-2 is a cross-scanning radiometer. To collocate ISCCP to SSM/T-2 data, we use the averages of all pixels (usually about 10) within the range of $0.4^{\circ}$ radius to the center of SSM/T-2 pixel. The maximum time difference is $1.5 \mathrm{~h}$ due to the 3-hourly sampling of ISCCP data. It should be cautioned that there are potential mismatches between ISCCP and SSM/T-2 data due to the time difference and the sampling procedure used in ISCCP (Rossow et al. 1996). An improvement could be done in the future by applying an ISCCP-like analysis to original high-resolution data. A total of 430613 such collocated data pairs are obtained for the region of $15^{\circ} \mathrm{S}-15^{\circ} \mathrm{N}, 130^{\circ} \mathrm{E}-180^{\circ}$ during TOGA COARE IOP.

In addition, vertical profiles of temperature and relative humidity from the European Centre for MediumRange Weather Forecasts (ECMWF) analyses are used to assist in determining the altitude of the liquid cloud. ECMWF data are available twice a day (at 0000 and $1200 \mathrm{UTC})$ at $2.5^{\circ} \times 2.5^{\circ}$ resolution. This dataset is made available through the TOGA COARE Data Archive Center.

\section{Ice water path retrieval method}

Liu and Curry (1998) presented a method to retrieve IWP by using airborne MIR data, which operates at similar frequencies to SSM/T-2 except that MIR has a higher frequency at $220 \mathrm{GHz}$. The algorithm is based on the results of radiative transfer model simulations using in situ ice particle properties as model inputs. They pointed out that the major uncertainties in the algorithm are those introduced by the unknown of the ice particle size and the existence of supercooled liquid water. In this study, we follow the same general methodology while making modifications by classifying clouds into different types and including adjustments for the cloud types that possibly contain supercooled cloud water. Evans and Stephens (1995b) and Deeter (1997) proposed a method to retrieve both ice water and particle size simultaneously. However, the proposed frequencies have not been available on satellites so far. Therefore, the ice particle size effect still remains unsolved in this study and is believed to cause the greatest uncertainty in the algorithm. According to the error assessment done by Liu and Curry (1998), this error could be about $\pm 50 \%$ of the retrieved IWP given the same variability of particle size as that observed during CEPEX. In addition, error associated with retrievals from satellite data is expected to be much larger than that associated with retrievals from airborne data because of the much larger footprint of satellite data. Clouds can hardly be uniform within an SSM/T-2 footprint ( $\geq 54$ $\mathrm{km})$.

The cloud classification is based on cloud-top temperature and a microwave index combining emission and scattering signatures (Liu et al. 1995). A conceptual

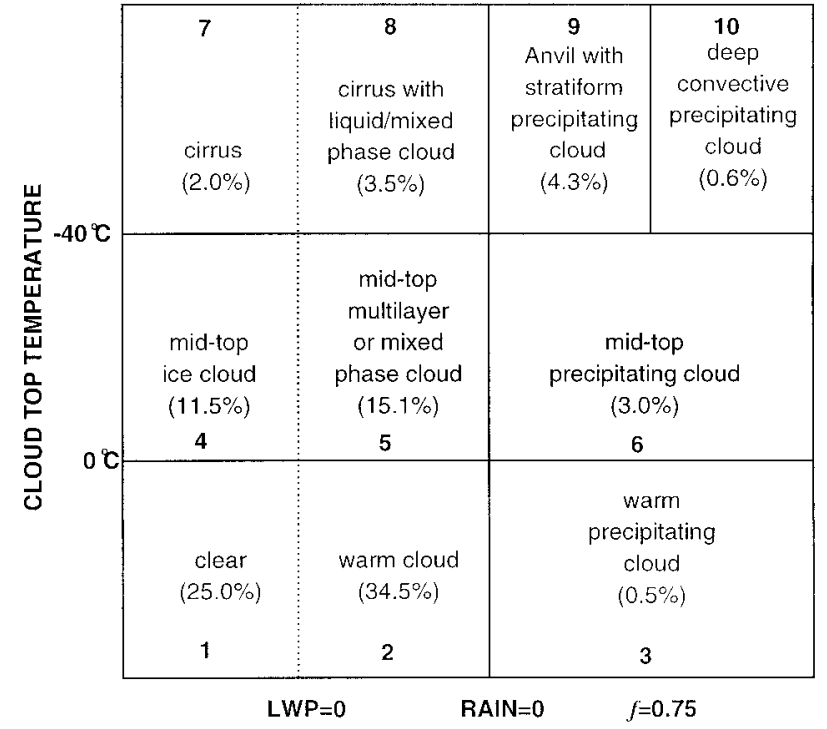

FIG. 1. Conceptual diagram of the cloud classification scheme used in this study. Microwave index, $f$, is the same as that defined in Liu et al. (1995). The values shown in the bracket indicate the percentage of pixel number in corresponding class.

diagram of the cloud classification is shown in Fig. 1. In this study we add a criterion of cloud LWP to distinguish between clouds with liquid water and those without liquid water. LWP is calculated from SSM/I data according to Liu and Curry (1993). Because the LWP $=0$ line does not correspond a fixed microwave index $(f)$, a dotted line is used for the boundary between with and without liquid water. We also assigned a number for each cloud class (as 1, 2, 3, . , 10), for later reference. We further divide the clouds into the following four groups for the purpose of IWP algorithm development:

1) classes 1, 2, and 3: clear or warm clouds without ice;

2) classes 4 and 7: ice clouds without liquid water;

3) classes 5 and 8: mixed-phase cloud with liquid cloud droplets and ice particles possibly being in the same layer (class 5), or ice cloud over liquid cloud (class 8); and

4) classes 6, 9, and 10: precipitating clouds with a deep layer of mixed-phase cloud above freezing level.

The brightness temperature depression at $150 \mathrm{GHz}$ is the primary parameter for the IWP retrieval, which is expressed as (Liu and Curry 1996, 1998)

$$
\beta=\frac{T_{B 0}-T_{B}}{T_{B 0}-240},
$$

where $T_{B}$ and $T_{B 0}$ are, respectively, the $150-\mathrm{GHz}$ brightness temperatures under conditions with and without ice. Here, $T_{B 0}$ is derived from a scatterplot of 90-versus $150-\mathrm{GHz}$ brightness temperatures following Liu and 


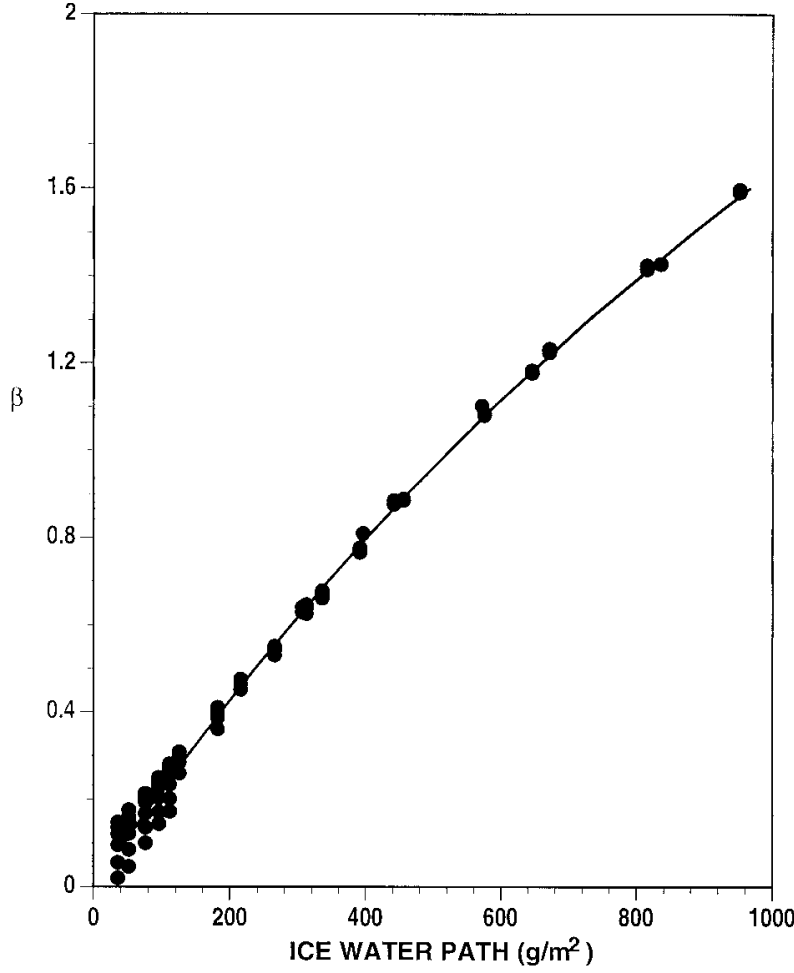

Fig. 2. Scatterplot of $\beta$ vs IWP for classes 4 and 7. The fitting curve is also shown.

Curry (1998). More discussions of $\beta$ can be found in Liu and Curry (1998).

The relationship between $\beta$ and IWP is established based on radiative transfer model results. A 32-stream polarized discrete ordinate method is used for solving the radiative transfer model. This model was described and used in Liu (1998) for assessing the accuracy of a computationally fast model. In conducting the model calculation, a standard tropical atmosphere over flat ocean surface is assumed. The relative humidity in the atmosphere can vary from $30 \%$ to $100 \%$ below $5 \mathrm{~km}$ and from $10 \%$ to $100 \%$ above $5-\mathrm{km}$ altitude. The following two liquid water cloud layers are possible depending on the class groups defined above: 1) low cloud can be between 1 and $4 \mathrm{~km}$ with its depth varying from 1 to $3 \mathrm{~km}$; 2) midcloud can be between 4 and $7 \mathrm{~km}$ with its depth varying from 1 to $3 \mathrm{~km}$. These locations of the possible liquid cloud layer are based on the analyses of TOGA COARE sounding data (Wang and Rossow 1995). The ice particle size distribution, the shape of vertical profile of ice water content, and mass median size of ice particles are adopted from Liu and Curry (1998). The particle size distribution and mass median diameter are functions of height (temperature). The $\beta$ IWP relation takes the following form:

$$
\mathrm{IWP}=\sum_{n=1}^{3} c_{n} \beta^{n}
$$

TABle 1 . Coefficients $c_{n}$

\begin{tabular}{lccc}
\hline \hline & $c_{1}$ & $c_{2}$ & $c_{3}$ \\
\hline Classes 4 and 7 & 444.166 & 46.6072 & 33.4566 \\
Class 5 & 482.912 & 2.62788 & 21.5002 \\
Class 8 & 558.295 & -114.544 & 75.5929 \\
Classes 6, 9, and 10 & 451.564 & -73.6763 & 19.7106 \\
\hline
\end{tabular}

where $c_{n}$ are the coefficients and are determined for each group of cloud classes as described below based on radiative transfer model simulations.

\section{a. Classes 4 and 7}

In this group there is no liquid water cloud. One hundred and eight (108) radiative transfer model runs are conducted, allowing an ice cloud to exist between 6 and $12 \mathrm{~km}$ with depth ranging from 1 to $3 \mathrm{~km}$ and ice water content ranging from 0 to 3 times the average profile given in Liu and Curry (1998). Figure 2 shows the $\beta$ IWP scatterplot and the fitting by (2) with the coefficients listed in Table 1.

\section{b. Classes 5 and 8}

Liquid water is detected in these cloud classes. A reasonable assumption is that class 5 consists of a mixed-phase midlevel cloud and/or a low liquid water cloud, while class 8 consists of a high-level ice cloud overlying a mid- and/or a low-level liquid water cloud. Radiative transfer model results (Liu and Curry 1998) showed that the midlevel liquid water cloud (with supercooled liquid water) could produce significant error in the retrievals if it is not taken into account. The strategy of our algorithm development for this cloud group is that we first assume low-level cloud only to retrieve a first guess IWP [coefficients for Eq. (2) are listed in Table 1], then adjust the first guess using midlevel liquid cloud information obtained from SSM/I and ECMWF data.

We conducted 2070 model runs with LWP in lowlevel cloud varying from 0 to $400 \mathrm{~g} \mathrm{~m}^{-2}$ and in midlevel cloud from 0 to $480 \mathrm{~g} \mathrm{~m}^{-2}$. The ice layer is assigned to ranging from 6 to $10 \mathrm{~km}$ with maximum depth of 3 $\mathrm{km}$ and IWP ranging from 0 to $1000 \mathrm{~g} \mathrm{~m}^{-2}$. Using these radiative transfer model results, errors caused by ignoring midlevel cloud in the retrieval are simulated and shown in Fig. 3a for both classes 5 and 8. In this figure three kinds of symbols are used for three midlevel liquid water situations [i.e., LWP in midlevel $\left(\mathrm{LWP}_{m}\right)$ equals 160,320 , and $480 \mathrm{~g} \mathrm{~m}^{-2}$ ]. It is seen that the midlevel supercooled liquid water has different effects on retrieval errors for class 5 and class 8 clouds. For class 8 clouds, in which the ice cloud overlies the supercooled liquid cloud layer, the midlevel liquid water causes overestimation and the magnitude of error does not seem to be related to IWP. This is because the supercooled liquid water acts only to lower the nonice background bright- 

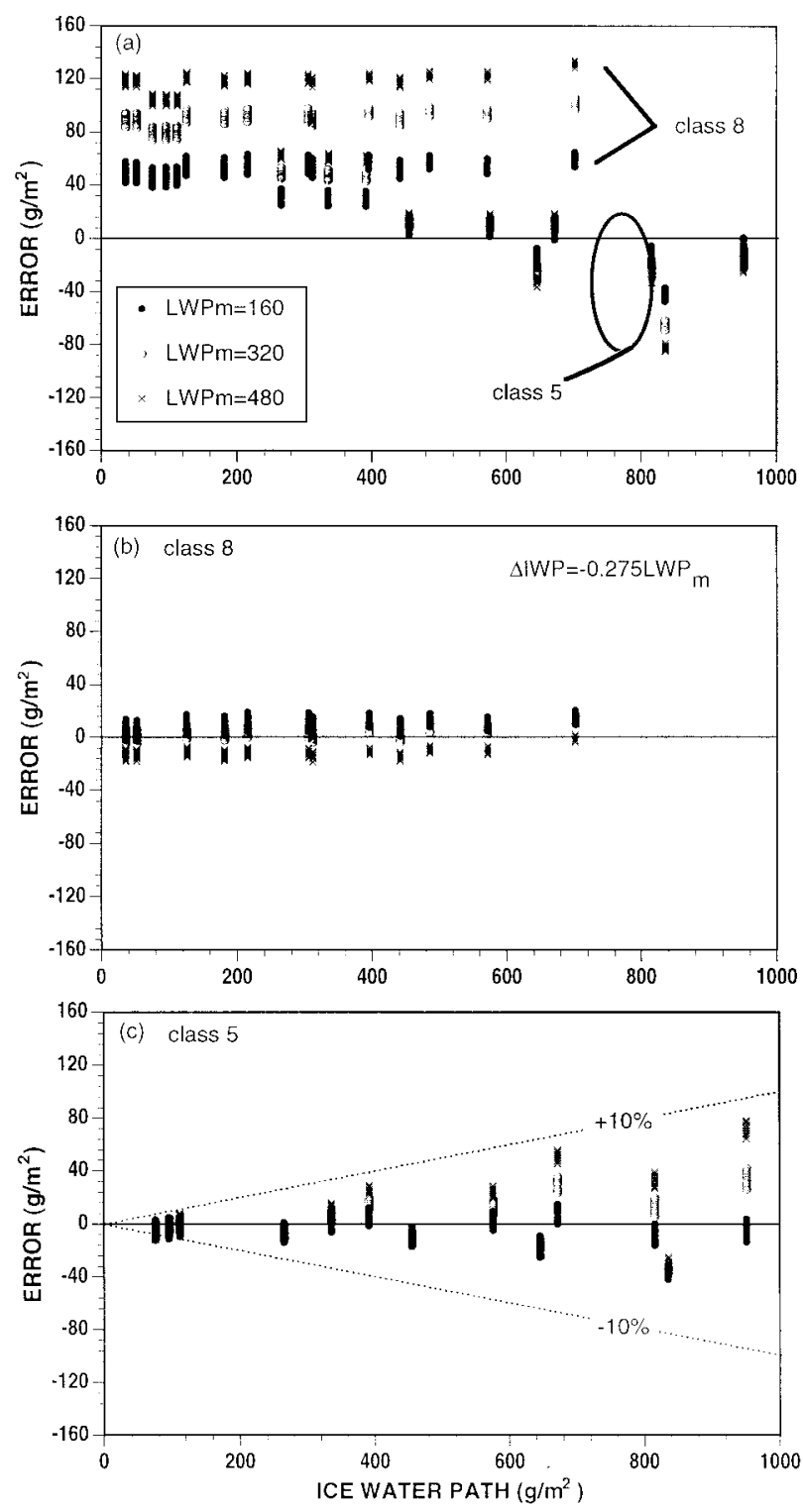

FIG. 3. (a) Errors caused by ignoring midlevel liquid water clouds, (b) error for class 8 cloud after correction, and (c) error for class 5 cloud after correction.

ness temperature, but not to weaken the scattering signal that reached to satellite. On the other hand, for class 5 cloud, in which the supercooled liquid water exists in the same cloud layer as the ice particles, the midlevel liquid water causes overestimation for small IWPs and underestimation for large IWPs. Supercooled liquid water has two effects on the upwelling radiance in this case: lowering nonice background radiation (decreasing brightness temperature) and weakening scattering by ice particles (increasing brightness temperature). The first effect dominates over the second one when IWP is small $\left(<500 \mathrm{~g} \mathrm{~m}^{-2}\right)$ and the opposite is true when IWP becomes large.

Let us assume that $\mathrm{LWP}_{m}$ (LWP in the midlevel cloud) is known. We could minimize the error by applying an adjustment ( $\triangle$ IWP) to the first guess. Figure $3 \mathrm{~b}$ shows the error after applying the following adjustment to class 8 cloud:

$$
\Delta \mathrm{IWP}=-0.275 \mathrm{LWP}_{m},
$$

and Fig. $3 \mathrm{c}$ shows the error after applying the following adjustment to a class 5 cloud:

$$
\Delta \mathrm{IWP}=-3.0 \times 10^{-2} \mathrm{LWP}_{m}+1.5 \times 10^{-5} \mathrm{LWP}_{m}^{2} .
$$

The improvements for class 8 retrievals are significant and the theoretical error after the adjustment is only about $\pm 20 \mathrm{~g} \mathrm{~m}^{-2}$. For class 5 , the adjustment manages to remove the bias and keep the error within $\pm 10 \%$ of the IWP.

LWP in the midlevel $\left(\mathrm{LWP}_{m}\right)$ is not derived directly from satellite observations in this study. Instead, we first calculate total LWP $\left(\mathrm{LWP}_{t}\right)$ from SSM/I data (Liu and Curry 1993), and then partition $\mathrm{LWP}_{t}$ into low- and midlevel based on the ECMWF relative humidity vertical profile. Sheu et al. (1997) used a "cloudiness likelihood" parameter (LC) to determined cloud layers based on relative humidity (RH) and a pressure-dependent constant. We adopt the same idea to assign possible cloud layers in this study. Using ECMWF vertical relative humidity profile, we first find all layers below 7 $\mathrm{km}$ with $\mathrm{LC}>0.3$, which corresponds to $\mathrm{RH}>80 \%$ at $1000 \mathrm{mb}$ and $\mathrm{RH}>50 \%$ at $500 \mathrm{mb}$, and assume that these layers are possible liquid water cloud layers. The first guess of liquid water content $\left(\mathrm{LWC}_{g}\right)$ at each such level is calculated according to Karstens et al. (1994), that is,

$$
\mathrm{LWC}_{g}=\mathrm{LWC}_{\text {adi }}(1.239-0.145 \ln \Delta h),
$$

where $\mathrm{LWC}_{\text {adi }}$ is the adiabatic liquid water content and $\Delta h$ is the distance from the base of corresponding cloud layer. The final liquid water content profile, LWC, is then determined by normalizing $\mathrm{LWC}_{g}$ by a constant so that the integration of LWC over all levels equals the observed $\mathrm{LWP}_{t}$. LWP ${ }_{m}$ is then determined as the integrated liquid water above $4-\mathrm{km}$ altitude.

\section{c. Classes 6, 9, and 10}

Clouds in this group are much more complicated than others because the depth of the hydrometeors is deeper and variable depending on precipitation types (convective, stratiform, etc.). Therefore, greater uncertainties are expected. Evans et al. (1995) introduced a method to retrieve profiles of precipitating hydrometeors using microwave data, in which mesoscale model simulation results are used as a priori information. However, in this study we use the empirical method similar to those used in other cloud classes. A total of 882 radiative transfer model runs are conducted for this cloud group. In these model runs, low-level cloud LWP is fixed to $320 \mathrm{~g} \mathrm{~m}^{-2}$ and midlevel cloud LWP varies from 240 to $480 \mathrm{~g} \mathrm{~m}^{-2}$. 


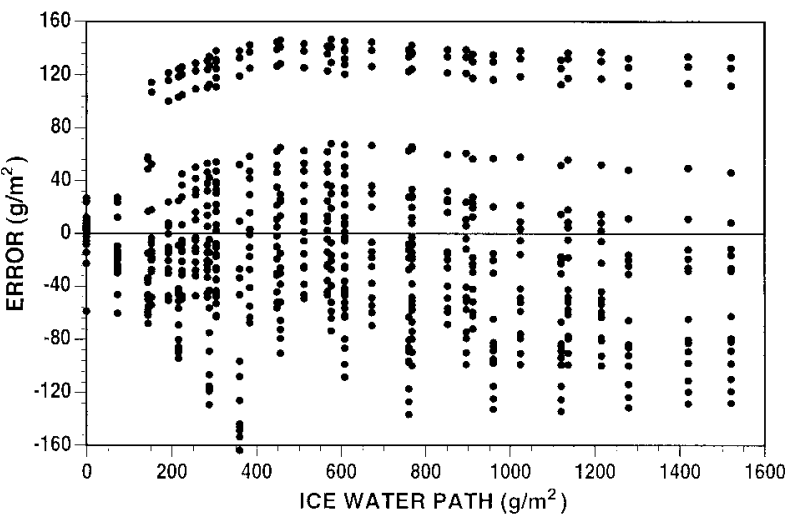

FIG. 4. Theoretical error for classes 6, 9, and 10 clouds.

Ice cloud is located in the layer of $5-12 \mathrm{~km}$, with its depth varying from 1 to $6 \mathrm{~km}$ and IWP from 0 to 1500 $\mathrm{g} \mathrm{m}^{-2}$. Rainfall rate is assigned to vary from 0 to 30 $\mathrm{mm} \mathrm{h}^{-1}$ and the rain layer is below the freezing level. Because the raindrops dominate the microwave emission, the values used for cloud water in this cloud group are less important. Following the same procedure as that described for other cloud groups, $c_{n}$ in (2) are determined and listed in Table 1.

The theoretical errors for classes 6, 9, and 10 determined using the results of these model runs are shown in Fig. 4. These errors are due to the different combinations of relative humidity, rainfall rate, liquid, and ice clouds. It is seen that the errors for precipitating clouds are significantly large compared to those of the nonprecipitating cloud groups. We believe that it could be very difficult to improve the retrievals of the precipitating cloud group without additional data (such as radar data) inputs. Therefore, the retrieved results of this cloud group should be interpreted with extra caution. It is also noted that IWP retrieved from this cloud group includes both cloud and precipitating ice particles.

\section{Comparison with ISCCP data}

There is no in situ ice water measurement available to validate the SSM/T-2 ice water algorithm. To check the performance of the algorithm we compare the retrievals with ISCCP optical depth and cloud-top temperature analyses. Since ISCCP analyses are also satellite-based data, the comparison is not a direct validation. However, this comparison does provide an indication about whether or not our retrievals are within a reasonable range.

To evaluate the thresholding ability and the random error of the algorithm, we calculate the frequency distribution of IWP (Fig. 5) for all clear-sky pixels as identified by ISCCP. The maximum frequency is centered near IWP being 0 with the distribution slightly skewed toward to the negative IWP side. The mean and standard deviation are $-5 \mathrm{~g} \mathrm{~m}^{-2}$ and $88 \mathrm{~g} \mathrm{~m}^{-2}$, respectively. About $99 \%$ of the clear-sky pixels have IWP between

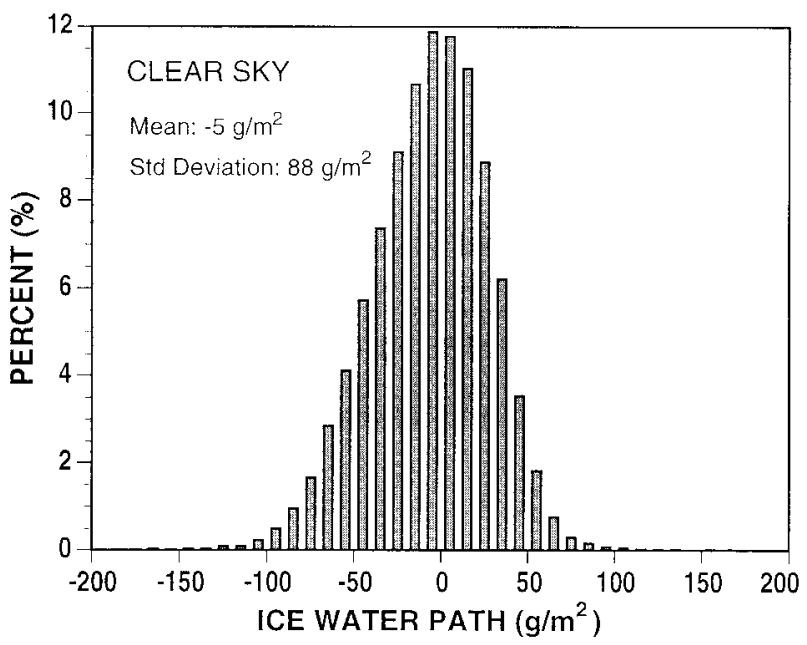

FIG. 5. Frequency distribution of IWP for clear-sky cases.

-100 and $80 \mathrm{~g} \mathrm{~m}^{-2}$. Therefore, it is expected that the random error is at least $\pm 100 \mathrm{~g} \mathrm{~m}^{-2}$ with no significant bias in the retrievals.

Figure 6 shows the averaged IWP in every $2^{\circ} \mathrm{C}$ cloudtop temperature bin for all available collocated data points. The variation within a bin is indicated by thin lines of $\pm \sigma$ (standard deviation). IWP for classes 1,2 , and 3 (warm clouds) is also calculated using algorithms for classes 4, 5, and 6, respectively. Negative IWP values for these classes are also plotted although they should be zero. The averaged IWP at cloud-top temperature of $0^{\circ} \mathrm{C}$ is near 0 . This again indicates that the threshold $\left(T_{B 0}\right)$ used in the algorithm can reasonably distinguish between ice and nonice conditions. On average, IWP increases with the decrease of cloud-top temperature, and precipitating clouds tend to have more ice than nonprecipitating clouds. This result is consistent with Liu and Curry's (1998) aircraft remote sensing result.

Another comparison is made with water path calculated from ISCCP optical depth. As described in section 2, there are two "optical depth" retrievals in the ISCCP analysis, TAU and TAUI, for clouds whose top temperature is colder than $273 \mathrm{~K}$. TAU is derived by assuming that cloud consists of only liquid water droplets while TAUI is derived by assuming all ice particles. Formulas for converting TAU and TAUI to water paths are provided in the ISCCP documentation (Rossow et al. 1996) as following:

$$
\mathrm{WPW}=6.292 \mathrm{TAU} \quad \mathrm{WPI}=10.5 \mathrm{TAU},
$$

where WPW and WPI are the water paths assuming liquid-only and ice-only clouds, respectively.

Figure 7 shows the comparison of the aforementioned ISCCP water paths with microwave water path (sum of SSM/I LWP and SSM/T-2 IWP). This comparison includes only the nonprecipitating clouds with cloud tem- 

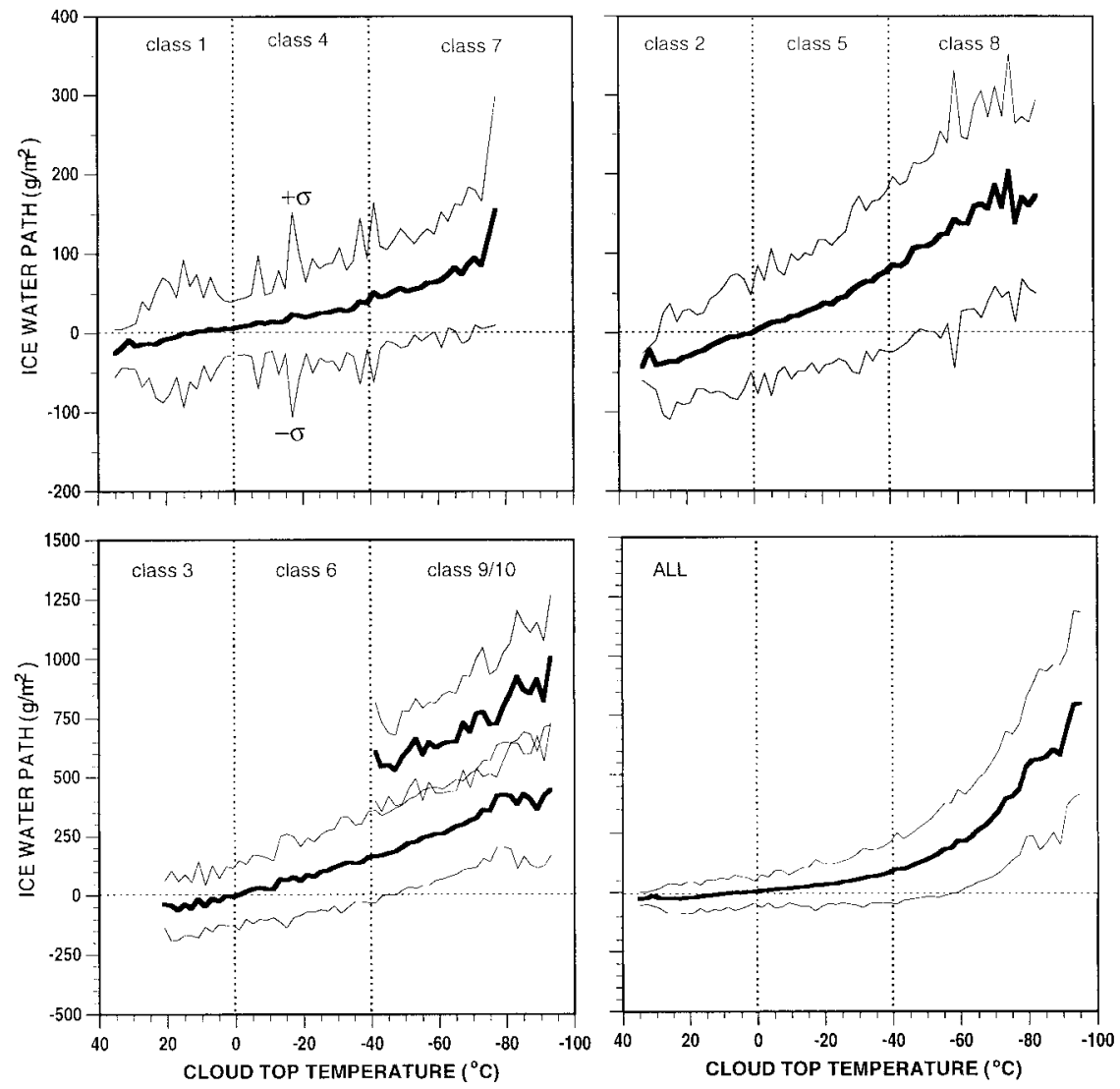

FIG. 6. Variations of averaged IWP vs cloud-top temperatures. The thin curves show plus and minus standard deviation $( \pm \sigma)$ from the mean.

perature colder than $260 \mathrm{~K}$. Each dot in this figure denotes an averaged microwave water path within a $20 \mathrm{~g}$ $\mathrm{m}^{-2}$ TAU/TAUI water path bin. The microwave water path compares reasonably well with ISCCP water path until $\mathrm{WPW} \approx 200 \mathrm{~g} \mathrm{~m}^{-2}$ (or TAU $\approx 32$ ) and WPI $\approx$ $300 \mathrm{~g} \mathrm{~m}^{-2}$ (or TAUI $\approx 29$ ). Clouds with TAU $>23$ and top higher than $440 \mathrm{mb}$ are classified as "deep convection" in the ISCCP classification (Rossow et al. 1996). Most of the cases with TAU $>32$ and TAUI $>$ 29 belong to this category because all cases used here have top temperatures colder than $260 \mathrm{~K}$. It is expected that greater uncertainties are associated with both microwave and ISCCP retrievals for clouds with TAU > 32. The reasons that SSM/I failed to classify them as "deep convection" could be 1) their sizes may be small so that the large field-of-view-averaged microwave signal is not strong enough for them to be classified as precipitating clouds; 2 ) there are possible miscollocation between microwave and ISCCP pixels, especially due to the time difference (maximum $1.5 \mathrm{~h}$ ). We need to interpret the result with caution. The scatterplot of original pixel data (instead of the binned data) shows significant scatter. The correlation coefficient is only about 0.4. Therefore, the relatively reasonable agreement between ISCCP analyses and our microwave retrievals only exists in an averaged sense. This may be due to visible channel (ISCCP) and microwave channel sensing the different portion of a cloud. While visible senses the top part of a cloud, microwave senses the whole column of the cloud. It is also noted that the comparison here is for the sum of liquid and ice water path. Error in any of the two components of microwave retrievals could result in a discrepancy.

In summary, the above comparisons show that the microwave IWP retrievals do not contradict the ISCCP analysis, and reasonable agreement is found between averaged ISCCP and microwave (SSM/I and SSM/T-2) total water path for nonprecipitating clouds. Lin and Rossow (1994) also reported a good agreement between SSM/I and ISCCP liquid water paths for warm nonprecipitating clouds. These comparisons only serve as a consistency check because ISCCP optical depth analysis is also a remote-sensed product.

\section{Relations between ice water path and other atmospheric hydrological parameters}

The amount of ice water in a cloud depends on many factors, such as the temperature, water vapor density, and liquid water content, etc. To better understand the 


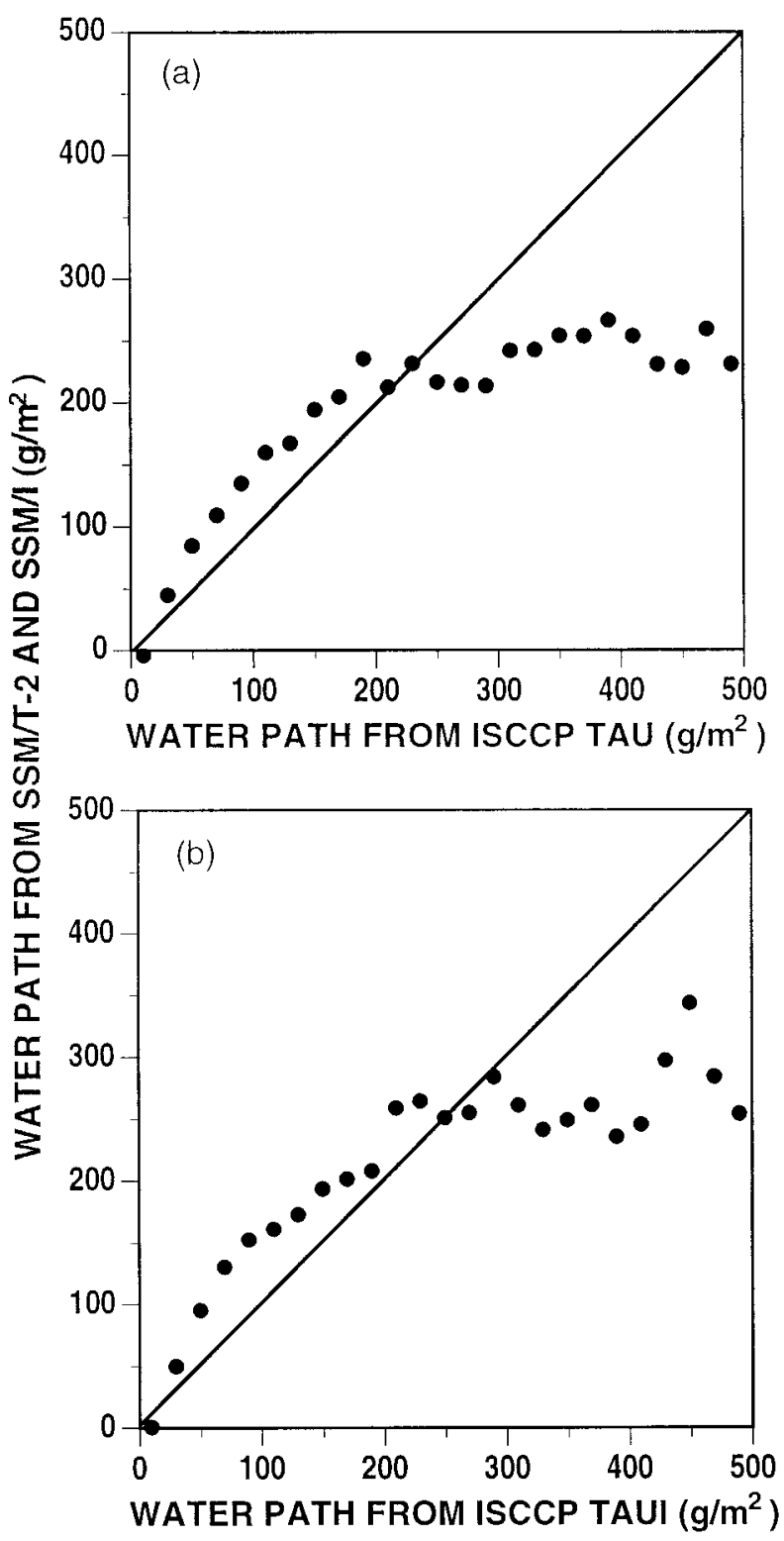

FIG. 7. Comparison of water paths calculated from microwave retrievals (IWP + LWP) with (a) those calculated from ISCCP TAU and (b) those calculated from ISCCP TAUI. Each dot denotes an averaged microwave water path within a $20 \mathrm{~g} \mathrm{~m}^{-2}$ TAU/TAUI bin.

cloud physical processes, we examine the relations among IWP and other atmospheric hydrological properties in this section. Most of these relations have not been available so far due to the lack of data.

\section{a. Cloud-top temperature}

The relation between IWP and cloud-top temperature is shown in Fig. 8 by two-dimensional frequency distributions for (a) all clouds, (b) nonprecipitating clouds, and (c) precipitating clouds. The isolines are for $\ln \left(n_{i j}\right)$, where $n_{i j}$ is the number of pixels that fall within the $i$ th (a) all clouds

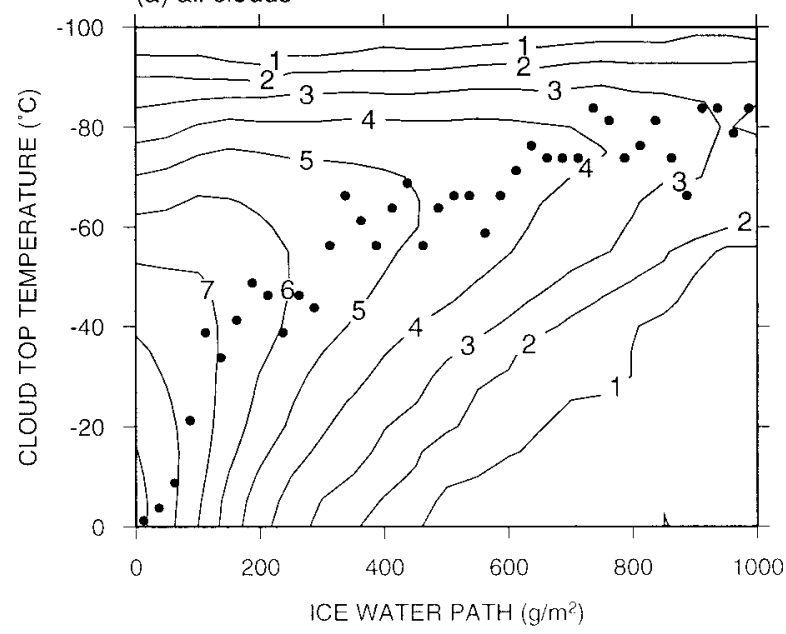

(b) nonprecipitating clouds

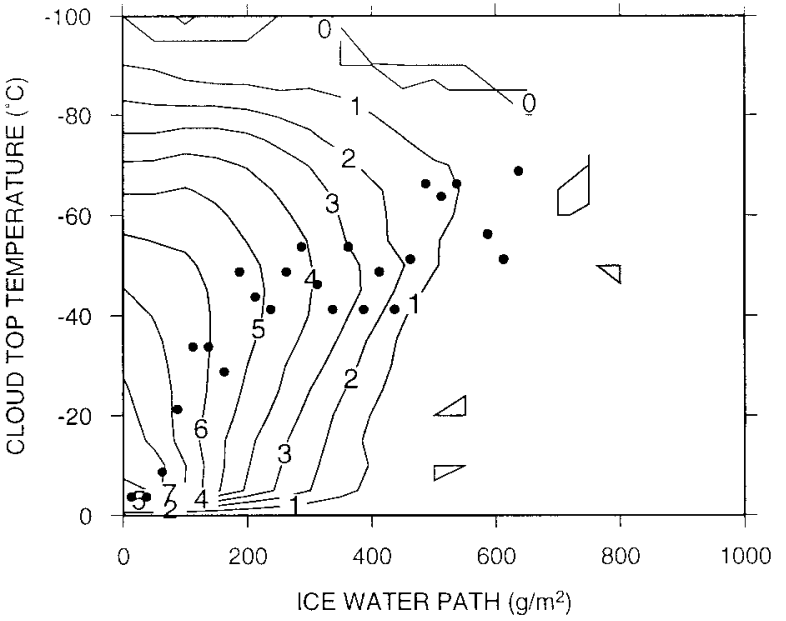

(c) precipitating clouds

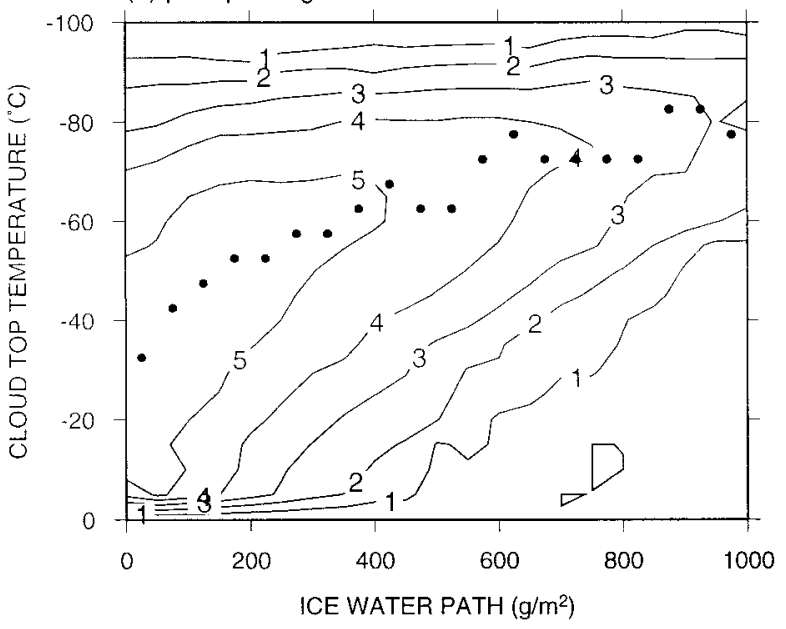

FIG. 8. Two-dimensional frequency distributions of cloud-top temperature vs IWP for (a) all clouds, (b) nonprecipitating clouds, and (c) precipitating clouds. The solid dots show the maximum frequency under each IWP bin. 
$50 \mathrm{~g} \mathrm{~m}^{-2}$ IWP-bin and $j$ th $5^{\circ} \mathrm{C}$ cloud-top temperaturebin. Therefore, the isolines of 8 and 1 indicate approximately 3000 and 3 pixels in a two-dimensional bin, respectively. The solid dots show the positions that have the maximum frequency at the given IWP bins. Similar diagrams are to be used throughout this section to show relations between two variables.

It is seen that IWP and cloud-top temperature are well correlated (although not linearly), especially for precipitating clouds. This is consistent with the results of Liu and Curry (1998) in which IWP is retrieved from airborne radiometry data. Using ISCCP data Rossow and Schiffer (1991) found that optical thickness is well related to cloud-top pressure. The result revealed from this study confirms their findings. However, Del Genio et al. (1996) showed that this correlation could not be produced in the National Aeronautics and Space Administration Goddard Institute for Space Studies's GCM that has a prognostic cloud water parameterization. As pointed out by Heymsfield and Platt (1984) and Liu and Curry (1998), on average colder clouds tend to have smaller ice water contents. Therefore, a reasonable explanation for the results in Fig. 8 could be that clouds with colder top temperatures are likely to have greater vertical extents, which leads to larger IWPs. This is particularly true when a cloud is precipitating and the precipitation-size ice particles are initiated near the cloud top. The correlative relation between IWP and cloud-top temperature for nonprecipitating clouds (correlation coefficient: 0.31 ) is not as close as that for precipitating clouds (correlation coefficient: 0.54) although the maximum frequency indicated by solid dots in Fig. 8b also shows a correlative relationship for clouds with top temperature warmer than $-40^{\circ} \mathrm{C}$.

For purpose of comparison, the frequency diagrams of (a) LWP versus cloud-top temperature for nonprecipitating clouds and (b) rainfall rate versus cloud-top temperature for precipitating clouds are shown in Fig. 9. In Fig. 9a, LWP in clouds with top temperatures warmer than $0^{\circ} \mathrm{C}$ shows an increasing trend with the decrease of cloud-top temperature. The relation determined from the maximum frequency (solid dots) shows that LWP increases from 0 to $1000 \mathrm{~g} \mathrm{~m}^{-2}$ while cloudtop temperature decreases from $22^{\circ}$ to $10^{\circ} \mathrm{C}$. The interpretation for these results follows: the common type for these warm clouds is boundary layer shallow convective clouds ( $\mathrm{St}, \mathrm{Cu}$, etc.) and their base heights are usually similar. Therefore, a higher cloud top often means a deeper cloud layer. Because of the convective nature of these clouds, a deeper cloud layer translates to a higher LWP. For clouds with top temperatures colder than $0^{\circ} \mathrm{C}$, cloud-top temperature shows little relationship with LWP. It is possible that some of the clouds are multilayer so that the cloud-top temperature for the top cloud layer does not necessarily have any connection with the liquid water amount down below. Cloud-top temperature shows significant skill in indicating rainfall rate particularly for heavier rainfall (Fig. 9b). The maximum fre- (a) nonprecipitating clouds

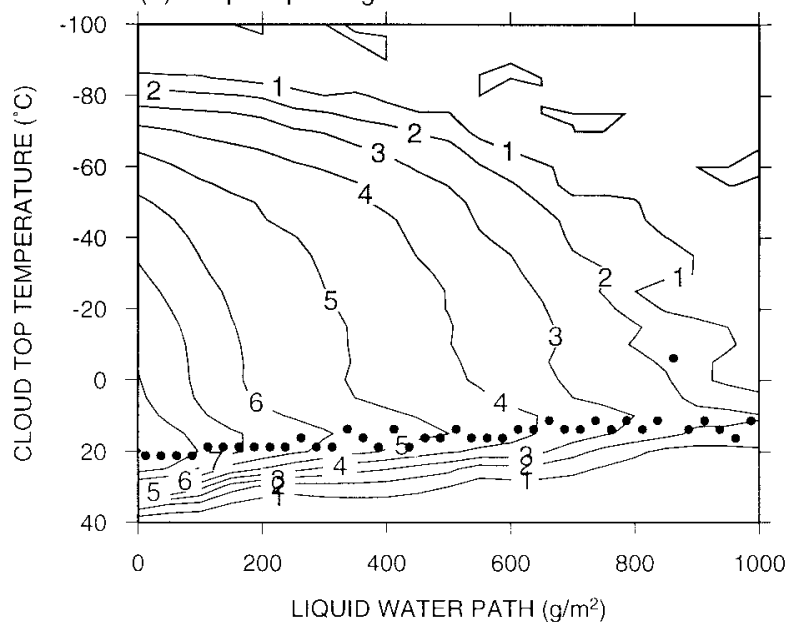

(b) precipitating clouds

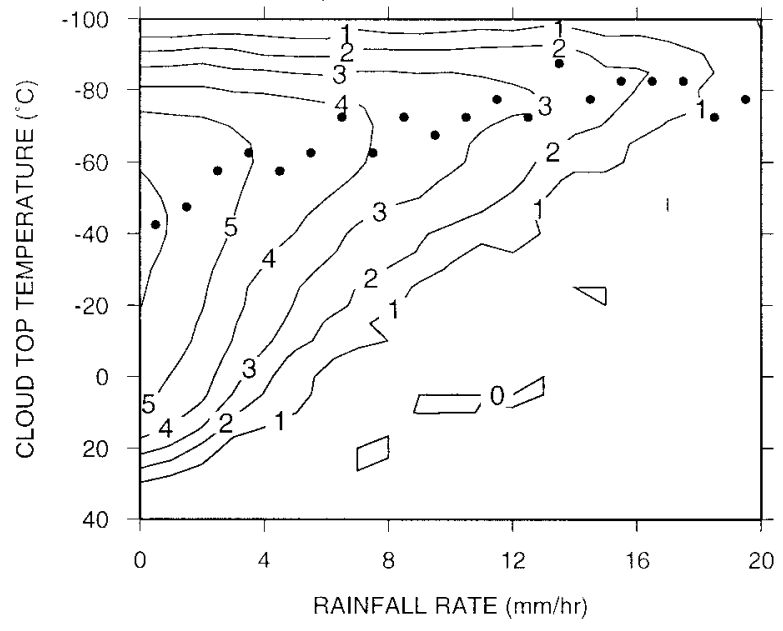

FIG. 9. Two-dimensional frequency distributions of cloud-top temperature vs (a) LWP for nonprecipitating clouds and (b) rainfall rate for precipitating clouds.

quency (solid dots) shows that rainfall "most likely" starts at cloud-top temperature of $-40^{\circ} \mathrm{C}$. Arkin and Meisner (1987) applied a rain threshold of $235 \mathrm{~K}$ $\left(-38^{\circ} \mathrm{C}\right)$ for their GOES Precipitation Index, which was developed also based on tropical clouds. In a sense, Fig. $9 \mathrm{~b}$ indicates the consistency in rain threshold between this study and theirs. However, it should also be noticed that for lower rainfall rates the number frequency in Fig. 9b spreads across a wide cloud-top temperature range. This wide range vividly shows the difficulty of retrieving instantaneous rainfall from cloud-top temperature alone.

\section{b. Liquid water path}

There is no clear correlation between IWP and LWP as shown in Fig. 10 in which Figs. 10a and 10b show the frequency diagrams for all nonprecipitating clouds 
(a) all nonprecipitating clouds

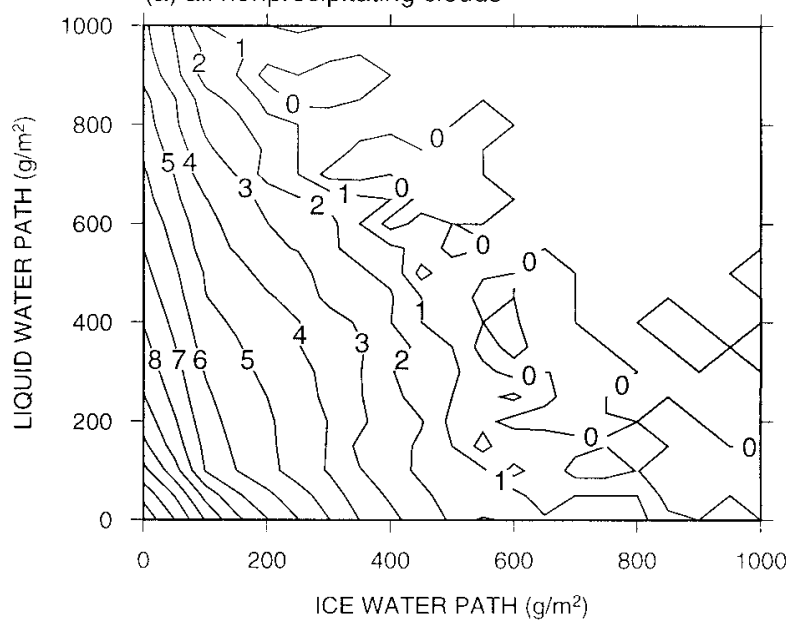

(b) cold nonprecipitating clouds

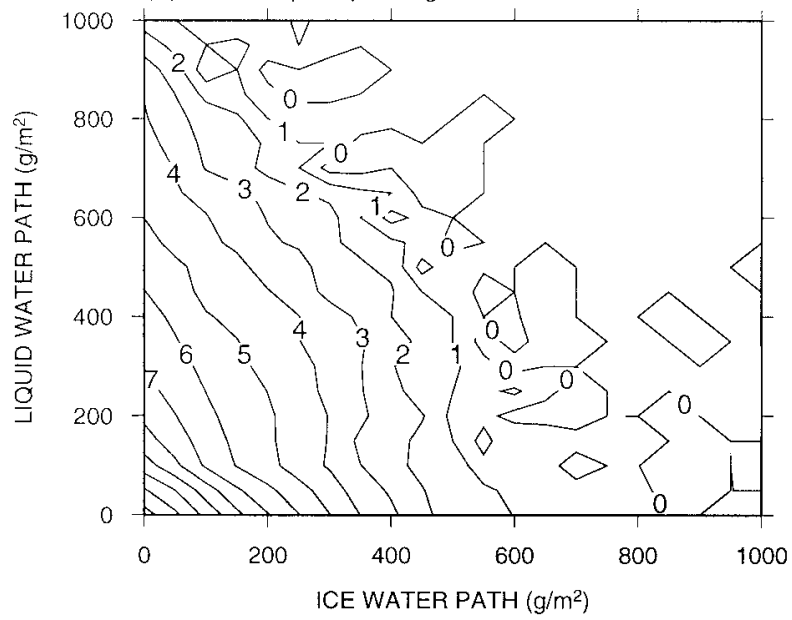

FIG. 10. Two-dimensional frequency distributions of LWP vs IWP for (a) all nonprecipitating clouds and (b) nonprecipitating clouds with top temperatures colder than $0^{\circ} \mathrm{C}$.

and nonprecipitating clouds with top temperature colder than $0^{\circ} \mathrm{C}$, respectively. The maximum frequency of occurrence is at LWP $=0$ and IWP $=0$, and the frequency decreases in a similar fashion toward any larger IWP and LWP combinations. There may be two situations that result in this kind of "randomly related" distribution. The first situation is multilayer clouds, in which the ice water in the top layer(s) has little connection to the liquid water in the lower layer(s). The second situation may be only one cloud layer, but the ratio of liquid versus ice water is rather dependent upon the cloud dynamics, and varies from case to case. In addition, inhomogeneity of clouds within an SSM/T-2 footprint may also contribute to the random relationship.

Figure 11 shows the frequency diagrams of (a) the total water path (IWP + LWP) and (b) glaciation ratio [defined as $100 \times \mathrm{IWP} /(\mathrm{IWP}+\mathrm{LWP})]$ versus cloudtop temperature. The primary maximum frequency is shown by solid dots and the secondary maximum fre- (a) all nonprecipitating clouds

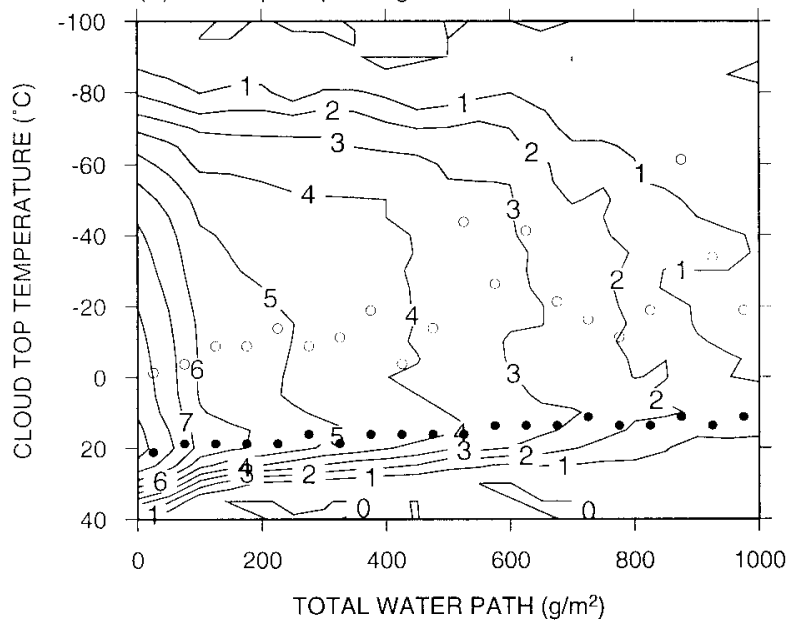

(b) cold nonprecipitating clouds

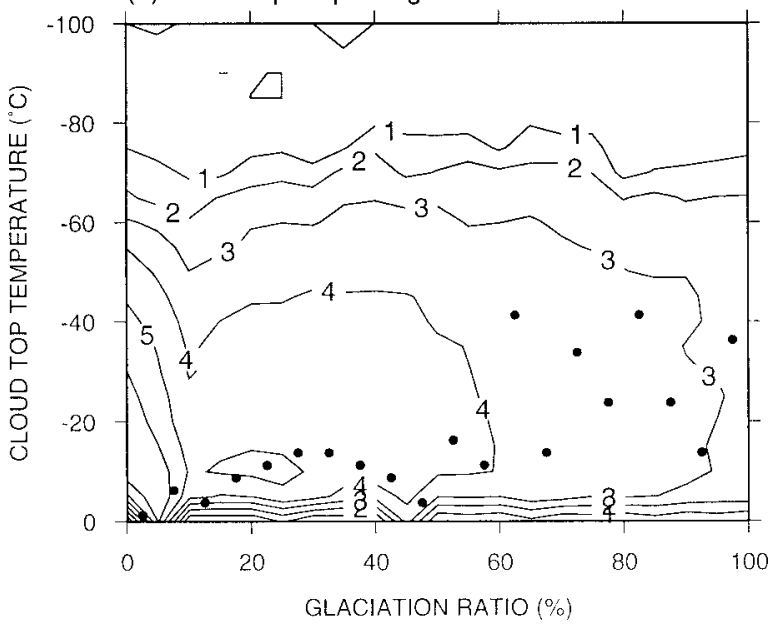

FIG. 11. Two-dimensional frequency distributions of cloud-top temperature vs (a) total water path and (b) glaciation ratio $[100 \times$ IWP/ (LWP + IWP)] for nonprecipitating clouds.

quency is shown by circles in Fig. 11a. For clouds with top temperature warmer than $0^{\circ} \mathrm{C}$, there is only liquid water. So, the correlation of total water path with cloudtop temperature is the same as that in Fig. 9a. For clouds with top temperature colder than $0^{\circ} \mathrm{C}$, there also seems to be some correlation although it is not as clear as for the warmer clouds portion. This correlation is determined by ice clouds (Fig. 8b). The glaciation ratio does not have a clear correlation with cloud-top temperature in Fig. 11b. This relationship was also investigated by Lin and Rossow (1996). They concluded that the ice fraction increases as the cloud-top temperature decreases on average over time ( 1 month) and space $\left(20^{\circ} \mathrm{S}-\right.$ $20^{\circ} \mathrm{N}$ belt). For comparison, we reexamine this relationship for the average of all available data. Figure 12 shows the glaciation ratio averaged in each $2.5 \mathrm{~K}$ cloudtop temperature bin. The averaged relationship shows an increase of glaciation ratio with the decrease of 


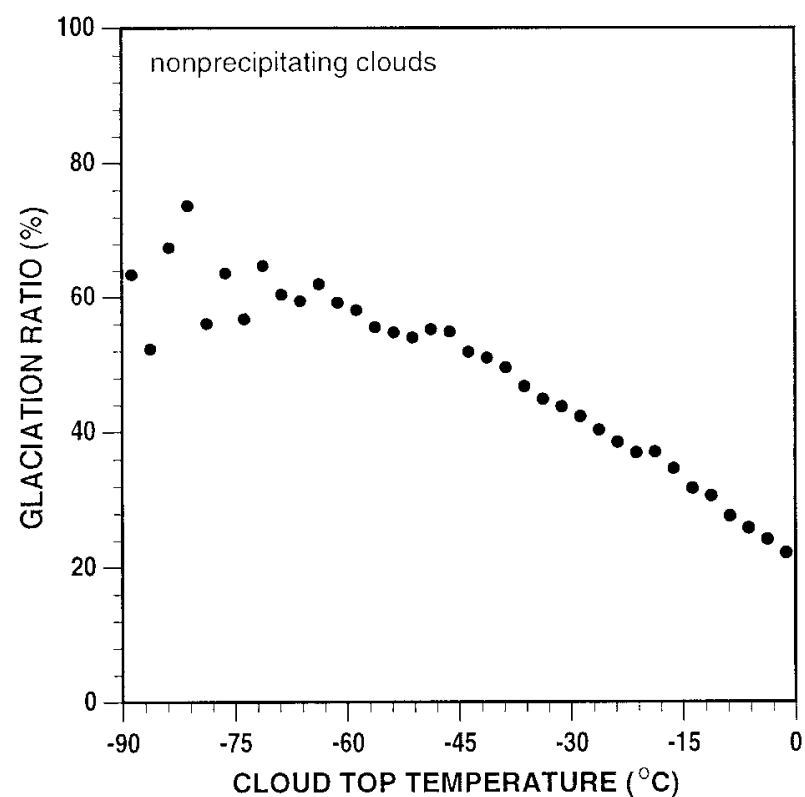

FIG. 12. Glaciation ratio averaged within each $2.5^{\circ} \mathrm{C}$ cloud-top temperature bin for all nonprecipitating clouds.

cloud-top temperature within the cloud-top temperature range of $0^{\circ}$ to $-50^{\circ} \mathrm{C}$, a similar result to that of Lin and Rossow (1996). From Figs. 11b to 12 we conclude that the glaciation ratio is negatively correlated to cloud-top temperature on an average of many clouds while this relationship differs substantially among individual cases. The difference reflects the important role of the vertical structure and cloud dynamics in determining the liquid-ice ratio in an atmospheric column.

It is also noted that the derived glaciation ratio is not 0 when cloud-top temperature is zero. Besides possible errors in IWP, LWP, and cloud-top temperature retrievals, another cause could be the inhomogeneity of clouds within a satellite footprint. Although the averaged cloud-top temperature is $0^{\circ} \mathrm{C}$, some parts of the cloud could have reached higher altitudes. Also, the glaciation ratio does not exceed about $70 \%$ even when cloud-top temperatures are colder than $-40^{\circ} \mathrm{C}$. One of the causes for this could be due to multilayer clouds.

\section{c. Rainfall}

The frequency diagram between IWP and rainfall rate is shown in Fig. 13. The two parameters show a very close correlation (correlation coefficient: 0.75) although there are cases with rainfall rate up to $5 \mathrm{~mm} \mathrm{~h}^{-1}$ but without measurable ice and cases with IWP up to 700 $\mathrm{g} \mathrm{m}^{-2}$ while without measurable rain. Therefore, in the most common situation in this region, a cloud having more ice above freezing level tends to be associated with more rain on the ground. The maximum frequency (solid dots) shows that rainfall rate is about 0 at IWP $=0$ and linearly increases to about $16 \mathrm{~mm} \mathrm{~h}^{-1}$ at IWP $=1000 \mathrm{~g} \mathrm{~m}^{-2}$.

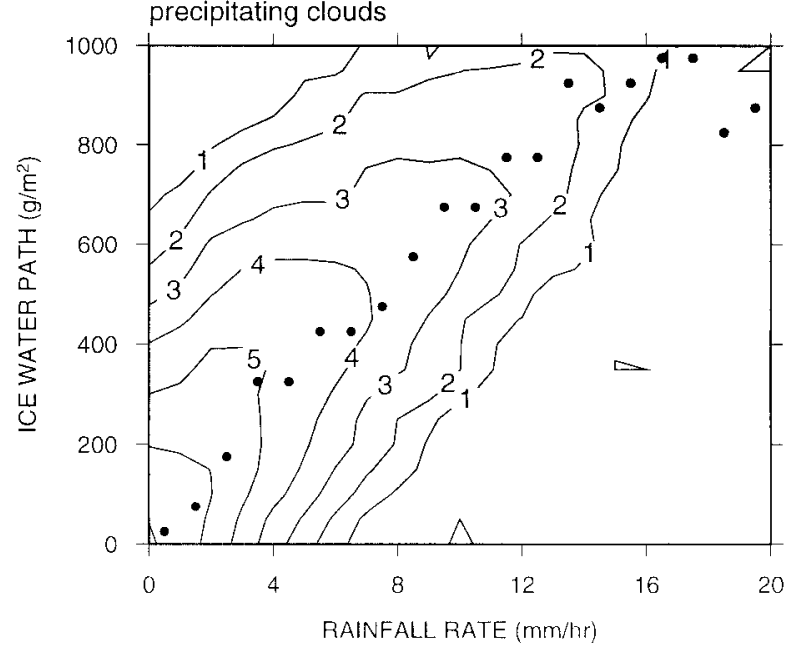

FIG. 13. Two-dimensional frequency distribution of IWP vs rainfall rate for precipitating clouds.

\section{d. Precipitable water}

The frequency diagrams of precipitable water versus (a) IWP, (b) LWP, and (c) cloud-top temperature for nonprecipitating clouds are shown in Fig. 14. Precipitable water varies from less than $20 \mathrm{~kg} \mathrm{~m}^{-2}$ to about 70 $\mathrm{kg} \mathrm{m}^{-2}$. High IWP values are found in the figure only when the precipitable water is large. Comparing to LWP in Fig. 14b, high IWP values can be found in a much narrower spectrum of precipitable water. For precipitable water less than $40 \mathrm{~kg} \mathrm{~m}^{-2}$, IWP reaches only about $100 \mathrm{~g} \mathrm{~m}^{-2}$ while LWP could be as high as about 1000 $\mathrm{g} \mathrm{m}^{-2}$. Although the highest IWP and LWP values occur when precipitable water is around its highest value, the highest frequency of pixel occurrence is where the precipitable water is near its highest while IWP and LWP are the lowest ( 0 , i.e., no cloud). That is, a high precipitable water is not necessarily associated with a deeper (if any) cloud although a deep cloud is usually associated with high precipitable water.

\section{Conclusions}

An over-ocean IWP retrieval algorithm using SSM/ T-2 92 and $150-\mathrm{GHz}$ brightness temperatures is presented for tropical ice clouds. In the algorithm, clouds are first divided into 10 classes and four groups based on cloud-top temperature, LWP, and microwave index. Retrieval equations are then developed for each group from the results of a series of radiative transfer model runs in which atmospheric, cloud, and rain conditions vary in a reasonable range. For clouds in which supercooled liquid water may exist, further correction is done by incorporating SSM/I LWP retrieval and ECMWF humidity profile analysis.

The IWP retrievals are subsequently employed to investigate the relations between IWP and other atmospheric hydrological parameters including cloud-top 
(a) cold nonprecipitating clouds

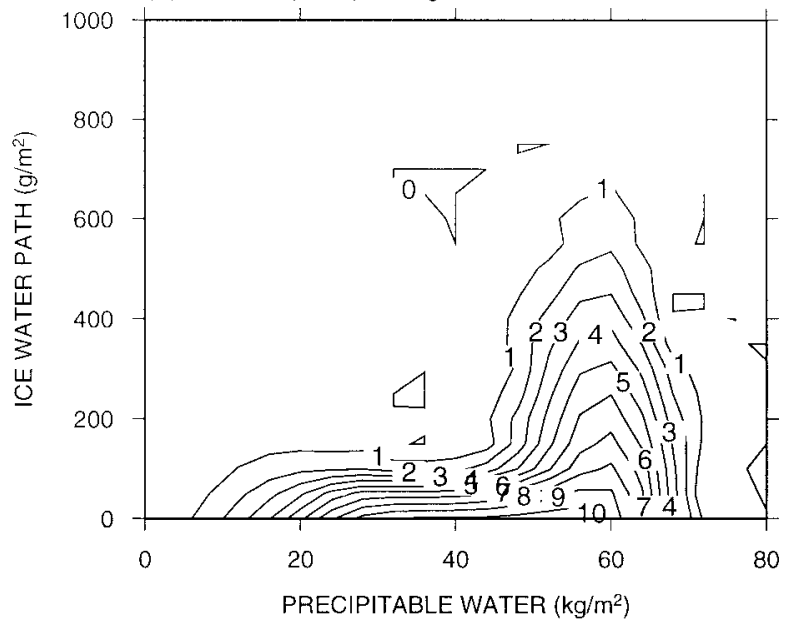

(b) all nonprecipitating clouds

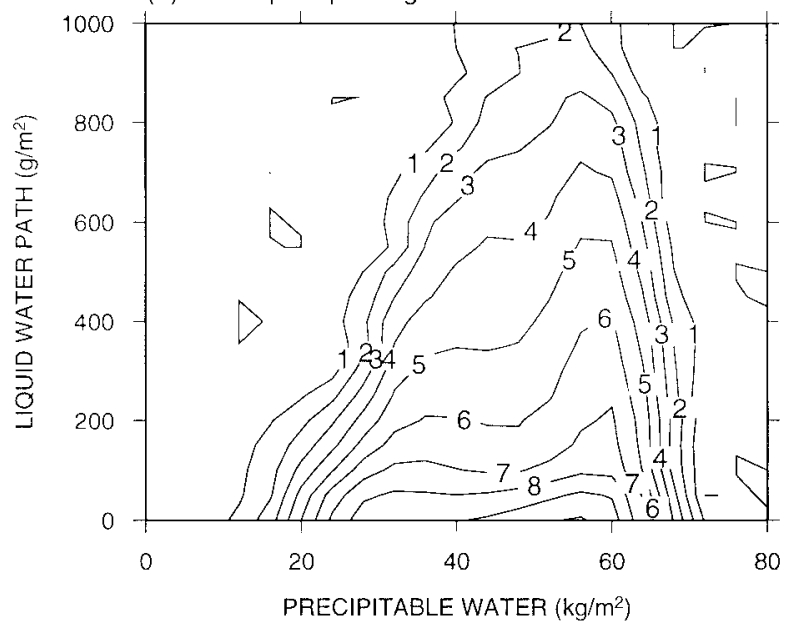

(c) all nonprecipitating clouds

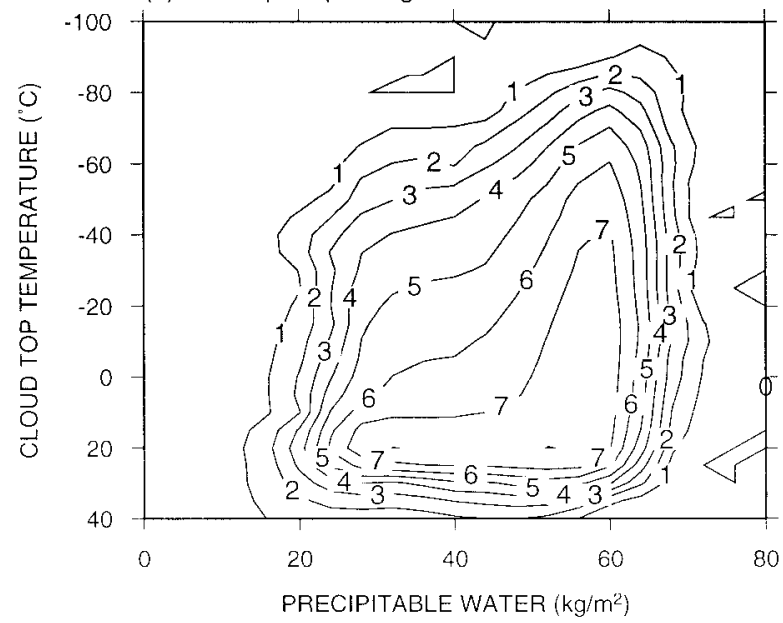

FIG. 14. Two-dimensional frequency distributions of (a) IWP, (b) LWP, and (c) cloud-top temperature vs precipitable water for nonprecipitating clouds. temperature, LWP, rainfall rate, and precipitable water. The relations are shown in two-dimensional frequency distributions. A brief summary of the findings are as follows.

IWP tends to increase with the decrease of cloud-top temperature and this relation is particularly evident for precipitating clouds. It is interpreted that clouds with colder cloud-top temperatures are likely to have deeper cloud layers, in turn, larger IWPs. LWPs retrieved for nonprecipitating clouds have a similar tendency but only for those with top temperatures warmer than $0^{\circ} \mathrm{C}$. There is no clear relation between IWP and LWP. The ratio of IWP to total condensed water (IWP + LWP) is negatively correlated to cloud-top temperature (only for cloud-top temperature $>-50^{\circ} \mathrm{C}$ ) on an average of a large data volume. However, this correlation becomes rather insignificant for individual cases. Rainfall rate has a strong correlation with IWP. These relations can be used to test and validate cloud parameterizations in numerical models, especially for nonprecipitating clouds. Moreover, a detailed comparison of these results with those produced by numerical models could help us to better understand the cloud and precipitation processes. This will be one of our future research topics.

In interpreting the aforementioned results, we should keep in mind the errors associated with the algorithm and introduced by imperfect datasets. The data used in this study are collected by different sensors with different scanning and sampling methods. ISCCP analyses and microwave data are from different satellites, which introduces time difference up to $1.5 \mathrm{~h}$. In addition, SSM/ $\mathrm{T}-2$ has a spatial resolution of more than $50 \mathrm{~km}$. Within one pixel, clouds are not uniform under most conditions. This subpixel inhomogeneity effect would also introduce error in our analyses. Therefore, continuous improvements for both the algorithm and the dataset quality are undoubtedly needed in future studies. In situ ice water measurements coincident with satellite passes in future field experiments will also be greatly helpful. Finally, sensors with better spatial resolution and scanning strategy as those onboard future National Polarorbiting Operational Environmental Satellite System satellites would also lead to better retrievals.

Acknowledgments. The authors would like to thank Dr. W. Rossow and three anonymous reviewers for their helpful comments. This research has been supported by NSF TOGA COARE Grant ATM-9525801 and NASDA ADEOS II Grant A0033.

\section{REFERENCES}

Alder, R. F., A. J. Negri, P. R. Keehn, and I. M. Hakkarinen, 1993: Estimation of monthly rainfall over Japan and surrounding waters from a combination of low-orbit microwave and geosynchronous IR data. J. Appl. Meteor., 32, 335-356.

Arkin, P. A., and B. N. Meisner, 1987: The relationship between largescale convective rainfall and cold cloud over the western hemisphere during 1982-84. Mon. Wea. Rev., 115, 51-74. 
Deeter, M. N., 1997: Millimeter-wave radiometric studies of tropical water variability and ice clouds. M.S. thesis, Dept. of Astrophysical, Planetary and Atmospheric Sciences, University of Colorado, 34 pp. [Available from University of Colorado, Boulder, CO 80309.]

Del Genio, A. D., 1997: Observational requirements for modeling of cloud feedbacks in global climate models. Proc. of WMO Workshop on Measurements of Cloud Properties for Forecasts of Weather and Climate, WMO/TD 852, D. Baumgardner and G. Raga, Eds., 403 pp.

—, M.-S. Yao, W. Kovari, and K. K.-W. Lo, 1996: A prognostic cloud water parameterization for global climate models. J. Climate, 9, 270-304.

Evans, K. F., and G. L. Stephens, 1995a: Microwave radiative transfer through clouds composed of realistically shaped ice crystals. Part I: Single scattering properties. J. Atmos. Sci., 52, 2041-2057.

$\longrightarrow$, and - 1995b: Microwave radiative transfer through clouds composed of realistically shaped ice crystals. Part II: Remote sensing of ice clouds. J. Atmos. Sci., 52, 2058-2072.

— - J. Turk, T. Wong, and G. L. Stephens, 1995: A Bayesian approach to microwave precipitation profile retrieval. J. Appl. Meteor., 34, 260-279.

— S. J. Walter, A. J. Heymsfield, and M. N. Deeter, 1998: Modeling of submillimeter passive remote sensing of cirrus clouds. J. Appl. Meteor., 37, 184-205.

Falcone, V. J., and Coauthors, 1992: SSM/T-2 calibration and validation data analysis. Rep. 111, Phillips Laboratory, Hanscom Air Force Base, 108 pp. [Available from Phillips Laboratory, 29 Randolph Road, Hanscom AFB, MA 01731-3010.]

Grody, N. C., 1991: Classification of snow cover and precipitation using the Special Sensor Microwave/Imager (SSM/I). J. Geophys. Res., 96, 7423-7435.

Heymsfield, A. J., 1993: Microphysical structures of stratiform and cirrus clouds. Aerosol-Cloud-Climate Interactions, P. V. Hobbs, Ed., Academic Press, 2523-2549.

— , and C. M. R. Platt, 1984: A parameterization of the particle size spectrum of ice clouds in terms of the ambient temperature and the ice water content. J. Atmos. Sci., 41, 846-855.

—, and G. M. McFarquhar, 1996: On the high albedos of anvil cirrus in the tropical Pacific warm pool: Microphysical interpretations from CEPEX. J. Atmos. Sci., 53, 2401-2423.

Karstens, U., C. Simmer, and E. Ruprecht, 1994: Remote sensing of cloud liquid water. Meteor. Atmos. Phys., 54, 157-171.

Knollenberg, R. G., K. Kelly, and J. C. Wilson, 1993: Measurements of high number densities of ice crystals in the tops of tropical cumulonimbus. J. Geophys. Res., 98, 8639-8664.

Lin, B., and W. B. Rossow, 1994: Observations of cloud liquid water path over oceans: Optical and microwave remote sensing methods. J. Geophys. Res., 99, 20 907-20 927.

$\longrightarrow$, and - 1996: Seasonal variation of liquid water and ice water path in nonprecipitating clouds over oceans. J. Climate, 9, 2890-2902.

Liu, G., 1998: A fast and accurate model for microwave radiance calculations. J. Meteor. Soc. Japan, 76, 335-343.

- and J. A. Curry, 1992: Retrieval of precipitation from satellite microwave measurement using both emission and scattering. $J$. Geophys. Res., 97, 9959-9974.

- , and - 1993: Determination of characteristic features of cloud liquid water from satellite microwave measurements. $J$. Geophys. Res., 98, 5069-5092. $\longrightarrow$, and — 1996: Large-scale cloud features during January 1993 in the North Atlantic Ocean as determined from SSM/I and SSM/ T2 observations. J. Geophys. Res., 101, 7019-7032.

- , and - 1997: Precipitation characteristics in Greenland-Iceland-Norwegian Seas determined using satellite microwave data. J. Geophys. Res., 102, 13 987-13997.

$\longrightarrow$, and - , 1998: Remote sensing of ice water characteristics in tropical clouds using aircraft microwave measurements. $J$. Appl. Meteor., 37, 337-355.

— - $\longrightarrow$, and R.-S. Sheu, 1995: Classification of clouds over the western equatorial Pacific Ocean using combined infrared and microwave satellite data. J. Geophys. Res., 100, 13 811-13 826.

Matrosov, S. Y., T. Uttal, J. B. Snider, and R. A. Kropfli, 1992: Estimation of ice cloud parameters from ground-based infrared radiometer and radar measurements. J. Geophys. Res., 97, $11567-11574$.

— B. B. Orr, R. A. Kropfli, and J. B. Snider, 1994: Retrieval of vertical profiles of cirrus cloud microphysical parameters from Doppler radar and infrared radiometer measurements. J. Appl. Meteor., 33, 617-626.

McFarquhar, G. M., and A. J. Heymsfield, 1996: Microphysical characteristics of three cirrus anvils sampled during the Central Equatorial Pacific Experiment (CEPEX). J. Atmos. Sci., 53, 24242451.

Minnis, P., K. N. Liou, and Y. Takano, 1993a: Inference of cirrus cloud properties from satellite-observed visible and infrared radiances. Part I: Parameterization of radiance fields. J. Atmos. Sci., 50, 1279-1304.

— , P. W. Heck, and D. F. Young, 1993b: Inference of cirrus cloud properties from satellite-observed visible and infrared radiances. Part II: Verification of theoretical radiative properties. J. Atmos. Sci., 50, 1305-1322.

Petty, G. W., 1994: Physical retrievals of over-ocean rain rate from multichannel microwave imagery. Part II: Algorithm implementation. Meteor. Atmos. Phys., 54, 101-121.

Rossow, W. B., and R. A. Schiffer, 1991: ISCCP cloud data products. Bull. Amer. Meteor. Soc., 72, 2-20.

— , A. W. Walker, D. E. Beuschel, and M. D. Roiter, 1996: International Satellite Cloud Climatology Project (ISCCP) documentation of new cloud datasets. WMO/TD 737, 115 pp.

Rutledge, S. A., and P. V. Hobbs, 1983: The mesoscale and microscale structure and organization of clouds and precipitation in midlatitude cyclones. VIII: A model for the feeder-seeder process in warm frontal rainbands. J. Atmos. Sci., 40, 1185-1206.

Sheu, R.-S., J. A. Curry, and G. Liu, 1997: Vertical stratification of tropical cloud properties as determined from satellite. J. Geophys. Res., 102, 4231-4245.

Spencer, R. W., R. E. Hood, F. J. LaFontaine, E. A. Smith, R. Platt, J. Galliano, V. L. Griffin, and E. Lobal, 1994: High-resolution imaging of rain systems with the Advanced Microwave Precipitation Radiometer. J. Atmos. Oceanic Technol., 11, 849-857.

Vivekanandan, J., J. Turk, and V. N. Bringi, 1991: Ice water estimation and characterization using passive microwave radiometry. $J$. Appl. Meteor., 30, 1407-1421.

Wang, J., and W. B. Rossow, 1995: Determination of cloud vertical structure from upper-air observations. J. Appl. Meteor., 34, 2243-2258.

Webster, P. J., and R. Lukas, 1992: TOGA COARE: The Coupled Ocean-Atmosphere Response Experiment. Bull. Amer. Meteor. Soc., 73, 1377-1416. 